\title{
Tìm hiểu ngành thương mại điện tử trong thời kì Covid-19
}

\author{
Hoàng Phương Linh, Nguyễn Thuỳ Linh, Trương Khánh Linh \\ Phùng Thị Nhật Linh, Nguyễn Khánh Linh
}

Đại học Quốc gia

Ngày 12 Tháng Hai 2022

Preprint DOI: https://osf.io/btxmz

Sau đây chúng tôi sẽ trình bày về tình hình thương mại điện tử trong dịch bệnh và thực tế sự phát triển của các sàn thương mại điện tử tại Việt Nam nhằm thảo luận để phân tích, đánh giá và có góc nhìn rộng hơn đối với sự phát triển của thương mại điện tử.

\section{SỰ PHÁT TRIỂN CỦA THƯƠ'NG MẠI ĐIỆn TỬ TẠI VIỆT NAM}

\section{1. Điều kiện phát triển:}

Hiện nay, khi dịch bệnh Covid-19 diễn ra và kéo dài trong thời gian suốt 2 năm vừa qua, đất nước phải chống chọi với dịch bệnh từ nhiều phía: sức khoẻ cộng đồng, kinh tế, quản lý xã hội, du lịch,... Đồng nghĩa với đó là các hoạt động kinh tế - xã hội phải tạm thời đóng lại, người dân phải hạn chế hoặc tuân thủ giãn cách xã hội. Do đó, con người thích nghi với cuộc sống bình thường mới, dành nhiều thời gian hoạt động online hơn khiến cho số lượng người sử dụng thiết bị thông minh càng ngày càng tăng cao như smartphone, laptop, ipad,... Việc tiếp cận với thiết bị điện tử thông minh chính là cách đưa thương mại điện tử đến người tiêu dùng nhanh và hiệu quả nhất. Chỉ với một chiếc smartphone có kết nối internet thì mọi người đều có thể nhận thông tin trực tuyến, mua sắm với những thao tác dễ dàng.

Nhiều trang thương mại điện tử du nhập vào Việt Nam, họ đều là những công ty lớn, có uy tín, có danh tiếng và cung cấp dịch vụ tốt và an toàn nhất. Những trang thương mại điện tử được marketing trên mọi phương tiện xã hội: đài báo, truyền hình, quảng cáo,... khiến mọi người tò mò, tìm hiểu và sử dụng. Hầu hết hiện tại, các trang thương mại điện tử khi đã tiến vào thị trường Việt Nam đã tìm hiểu và định ra chiến lược phát triển phù hợp với thị yếu của người Việt nên hầu hết mọi 
người đều không gặp khó khăn trong việc sử dụng chúng. Ngành thương mại điện tử đã rất thành công trong việc kết hợp marketing và công nghệ thông tin để tạo một hiệu ứng phủ sóng toàn quốc và thành công đó rất dễ nhìn thấy trong thực trạng mua sắm online ở nước ta.

Dịch bệnh khiến con người bị hạn chế di chuyển để tránh lây lan, họ online trên các nền tảng mạng xã hội và mua hàng online nhiều hơn. Họ nhận ra sự tiện dụng của những trang thương mại điện tử và dần thích nghi rồi sử dụng chúng một cách rộng rãi như một phương thức mua sắm thông thường. Các trang thông tin chính thống và báo chí cũng đưa ra rất nhiều lợi ích để truyền thông cho các trang thương mại điện tử về việc sử dụng nó tiện ích và phù hợp trong thời kì dịch bệnh như thế nào. Tạo nên hiệu ứng đám đông, mọi người muốn theo kịp thời đại và sử dụng TMĐT một cách hiệu quả và thường xuyên.

Tại Việt Nam, với một đất nước đang phát triển, việc xuất nhập khẩu đang được đấy mạnh để tăng độ nhận diện thương hiệu của đất nước cũng như đưa đến cho người tiêu dùng những sản phẩm chất lượng từ các nước khác mà không còn phải rườm rà như: mua hàng xách tay, gửi hàng từ nước ngoài,... Vậy nên, người dân dễ dàng tiếp cận lượng hàng hoá phong phú cũng như chính hãng từ các trang thương mại điện tử.

Giao diện và cách sử dụng đơn giản của các trang thương mại điện tử được đưa vào các ứng dụng dễ dàng tải xuống và liên kết với ví điện tử, thẻ ngân hàng khiến cho việc mua sắm diễn ra dễ dàng hơn rất nhiều so với sử dụng tiền giấy. Nó thực sự linh hoạt và tiện lợi, tiết kiệm thời gian cho người mua và bán.

Thương mại điện tử là nền tảng cho người bán hàng dễ dàng tiếp cận và phát triển với nguồn vốn ít, tài nguyên nhiều, phù hợp nhiều lứa tuổi. Nguồn tài nguyên phong phú thu hút những người có nhu cầu bán hàng và khách hàng lớn (cung tăng thì cầu cũng tăng). Người mua và người bán đều chỉ cần ở nhà, online và vẫn có thể liên hệ với nhau để mua hàng vô cùng tiện lợi. Món hàng thì đều được chuyển đến tận nhà, nhanh chóng, thuận tiện và vẫn có những đảm bảo về chất lượng từ trang thương mại điện tử.

Khả năng sáng tạo và độ nổi tiếng, tầm ảnh hưởng của các KOL đã giúp thu hút người dùng nhiều hơn, đồng thời hỗ trợ tăng độ uy tín cho sàn thương mại điện tử lẫn thương hiệu. Hơn nữa, dịch vụ chuyển hàng đang được mở rộng từ Việt Nam đến nước ngoài, rất nhiều đơn vị chuyển hàng mọc lên như nấm, chính dịch vụ chuyển nhanh và tiện lợi này đã kích thích nguồn nhu cầu lớn mua sắm trên các trang thương mại điện tử và còn giải quyết một số lượng lớn người thất nghiệp. 


\section{Chính sách phát triển:}

Một là, tiếp tục hoàn thiện cơ chế, chính sách, rà soát, bổ sung, sửa đổi và ban hành mới các chính sách, văn bản quy phạm pháp luật theo hướng tạo điều kiện, khuyến khích, hỗ trợ các hoạt động ứng dụng thương mại điện tử và các mô hình kinh doanh mới trên nền tảng công nghệ số.

Hai là, nâng cao năng lực quản lý và tổ chức hoạt động thương mại điện tử, đấu tranh chống các hành vi gian lận thương mại, xâm phạm quyền sở hữu trí tuệ và cạnh tranh không lành mạnh trong thương mại điện tử.

Ba là, xây dựng thị trường và nâng cao lòng tin người tiêu dùng trong thương mại điện tử thông qua tuyên truyền, đào tạo kỹ năng thương mại điện tử cho người dân và doanh nghiệp; Tổ chức các sự kiện thương mại điện tử thường niên mang tính kích cầu cho thị trường trong nước và mở rộng cho hoạt động thương mại điện tử xuyên biên giới, tạo môi trường cho các tổ chức, doanh nghiệp trình diễn những công nghệ mới nhất và các mô hình thương mại điện tử tiên tiến để người tiêu dùng trải nghiệm, xây dựng thói quen, kỹ năng thương mại điện tử mới.

Bốn là, tăng cường năng lực các hệ thống hạ tầng và dịch vụ hỗ trợ cho thương mại điện tử với việc cải thiện hạ tầng dịch vụ chuyển phát và logistics cho thương mại điện tử, ứng dụng các công nghệ mới trong hoạt động logistics; khuyến khích thí điểm và triển khai ứng dụng các phương tiện giao thông mới hỗ trợ việc vận chuyển, giao nhận hàng hóa trong thương mại điện tử; Xây dựng hệ thống quản lý trực tuyến các dịch vụ vận chuyển, giao nhận và hoàn tất đơn hàng cho thương mại điện tử bao phủ tất cả các tỉnh, thành phố trên cả nước.

Năm là, đẩy mạnh ứng dụng thương mại điện tử hỗ trợ các ngành hàng xuất khẩu chủ lực, mở rộng tiêu thụ cho hàng hóa nội địa và thúc đẩy phát triển thương mại điện tử tại các địa phương.

Sáu là, tuyên truyền, đào tạo kỹ năng thương mại điện tử cho người dân và doanh nghiệp. Tổ chức các sự kiện thương mại điện tử thường niên mang tính kích cầu cho thị trường trong nước và mở rộng cho hoạt động thương mại điện tử xuyên biên giới, tạo môi trường cho các tổ chức, doanh nghiệp trình diễn những công nghệ mới nhất và các mô hình thương mại điện tử tiên tiến để người tiêu dùng trải nghiệm, xây dựng thói quen, kỹ năng thương mại điện tử mới. 


\section{SỰ PHÁT TRIỂN THƯƠNG MẠI ĐIỆN TỬ TẠI CÁC QUỐC GIA KHÁC}

\section{Tình hình phát triển}

Từ khi các chính sách giãn cách xã hội được ban hành, nền tảng thương mại điện tử Mercado Libre của khu vực Mỹ Latinh đã ghi nhận doanh số hàng ngày tăng gấp đôi trong quý II/2020 so với cùng kỳ năm 2019. Còn nền tảng Jumia của châu Phi thông báo mức tăng $50 \%$ trong khối lượng giao dịch trong nửa đầu năm 2020.(Ban biên tập Thông tấn xã Việt Nam, 2021)

Tỷ trọng của thương mại điện tử trong doanh số bán lẻ của Trung Quốc tăng từ 19,4\% lên $24,6 \%$ trong giai đoạn từ tháng 8/2019 đến tháng 8/2020.

Còn ở Kazakhstan, tỷ trọng này đã tăng từ 5\% năm 2019 lên 9,4\% năm 2020. Thái Lan còn ghi nhận số lượt tải các ứng dụng mua sắm tăng đến $60 \%$ chỉ trong một tuần trong tháng 3/2020.(Ban biên tập Thông tấn xã Việt Nam, 2021)

Theo số liệu hằng quý do Bộ Thương mại Mỹ công bố mới đây, doanh số ngành thương mại điện tử của Mỹ đã tăng hơn 30\% trong khoảng thời gian từ quý I đến II-2020, mức tăng này là do tác động từ đại dịch Covid-19, đã thúc đẩy nhiều chi tiêu trực tuyến hơn.(Ngọc, 2020)

\section{Nhũng thách thức hiện nay}

Tại nhiều nước kém phát triển nhất thế giới, người tiêu dùng và doanh nghiệp lại không tận dụng được những cơ hội thương mại điện tử trong thời đại dịch do những rào cản cố hữu như:

- Các dịch vụ băng thông rộng đắt đỏ

- Sự phụ thuộc quá mức vào tiền mặt

- Thiếu niềm tin của người tiêu dùng

- Người dân thiếu kỹ năng về các thao tác với mạng Internet

- Chính phủ không chú trọng nhiều vào thương mại điện tử

\section{Chính sách phát triển}

a. Trên trường Quốc tế

Theo báo cáo của UNCTAD, xây dựng một hệ sinh thái thuận lợi cho thương mại điện tử những chính sách về:

- Cải thiện cơ sở hạ tầng thương mại và kỹ thuật số

- Tạo điều kiện thuận lợi cho các hình thức thanh toán số

- Xây dựng các khung quy định và pháp lý phù hợp cho các giao dịch trực tuyến

- Đảm bảo an ninh mạng

Trong 4 năm qua, sáng kiến eTrade for all của UNCTAD(UNCTAD, 2020), hiện đang được tài trợ bởi Hà Lan, Đức và Estonia đã hoạt động như một kênh hỗ trợ toàn cầu cho các nước đang phát triển nhằm san bằng sự chênh lệch về nguồn lực và thông tin về thương mại điện tử, cũng như xúc tiến quan hệ hợp tác giữa các đối tác. 
- Kể từ khi dịch COVID-19 bùng phát, hơn 30 đối tác của eTrade đã hợp tác với nhau để nâng cao nhận thức về các cơ hội thương mại điện tử và những nguy cơ nảy sinh trong cuộc khủng hoảng này.

b. Tù̀ phía Chính phủ

- Phần lớn chính phủ các nước ưu tiên những phản ứng ngắn hạn với đại dịch, nhưng nhiều nước cũng đã bắt đầu giải quyết những yêu cầu dài hạn về mặt chiến lược để có thể phục hồi.

- Tại Mỹ Latinh và Caribe, Chính phủ Costa Rica đã ra mắt một nền tảng dành cho các doanh nghiệp không hoạt động trực tuyến, và một ứng dụng trên điện thoại thông minh và dịch vụ nhắn tin nhằm tạo điều kiện thuận lợi cho hoạt động thương mại giữa các nhà sản xuất nông sản.(Ban biên tập Thông tấn xã Việt Nam, 2021)

- Còn tại châu Phi, Senegal đã thực hiện một chiến dịch thông tin, giáo dục và nâng cao nhận thức của mọi đối tượng người dân về những lợi ích của thương mại điện tử.(Ban biên tập Thông tấn xã Việt Nam, 2021)

- Trong khi đó, tại châu Á, Indonesia đã khởi động một chương trình xây dựng năng lực nhằm xúc tiến quá trình số hóa và chuyển đổi số ở các doanh nghiệp siêu nhỏ, nhỏ và vừa.(Ban biên tập Thông tấn xã Việt Nam, 2021)

c. Tù̀ phía các doanh nghiệp

- Không chỉ chính phủ mà các doanh nghiệp cũng phải tự tìm cách chuyển đổi số và hợp tác để thúc đẩy tiêu thụ sản phẩm trong thời đại lên ngôi của thương mại điện tử.

- Để đáp ứng nhu cầu ngày càng tăng của người tiêu dùng đối với dịch vụ đặt hàng trực tuyến và giao hàng tận nhà, tập đoàn phân phối Carrefour tại Bỉ đang tiếp cận những nhân tố mới trong lĩnh vực giao hàng siêu nhanh là Gorillas và DingDong.(Ban biên tập Thông tấn xã Việt Nam, 2021)

- Bên cạnh đó, Carrefour cũng đang dựa vào dịch vụ ShipTo (xe đạp giao hàng tại nhà trong 90 phút) và quan hệ đối tác với Deliveroo và Uber Eats.(Ban biên tập Thông tấn xã Việt Nam, 2021) 


\section{TÌNH HÌNH THỰC TẾ VỀ MộT Số SÀN THƯƠNG MẠI ĐIỆN TỬ TẠI VIỆT NAM.}

Nắm bắt xu hướng và tiềm năng phát triển của lĩnh vực TMĐT, các sàn TMĐT lớn tại Việt Nam đang cạnh tranh khốc liệt, ráo riết phát triển mình trong cuộc đua đầy hứa hẹn này. Trong đó, lưu lượng truy cập được xem như một trong nhưng thước đo thành công đối với các sàn TMĐT.

Theo báo cáo của iPrice Group, lưu lượng truy cập của TMĐT tại Việt Nam trong năm 2020 tăng trưởng rất mạnh do sự xuất hiện của dịch bệnh Covid-19 khiến thói quen của người tiêu dùng thay đổi, chuyển từ hình thức thương mại truyền thống sang hình thức TMĐT.

Bước sang Quý I/2021, tổng lưu lượng truy cập của 50 sàn TMĐT tại Việt Nam đạt 1,18 tỷ lượt, sụt giảm nhẹ $9 \%$ so với Quý IV/2020 trước đó. Trong khi đó, lưu lượng truy cập các sàn TMĐT giảm 4\% so với cùng kỳ năm ngoái. Tuy nhiên, đây là điều dễ hiểu bởi các sàn TMĐT hầu hết đều có các chương trình khuyến mãi và kích cầu tiêu dùng trong dịp mua sắm cuối năm. LƯU LƯợNG TRUY CÂP WEBSITE HÀNG THÁNG CỦA 4 SÀN THƯƠNG MẠI ĐIỆN TỬ
ĐUỰ̛̛C TRUY CẬP NHIÊU NHẤT VIỆT NAM

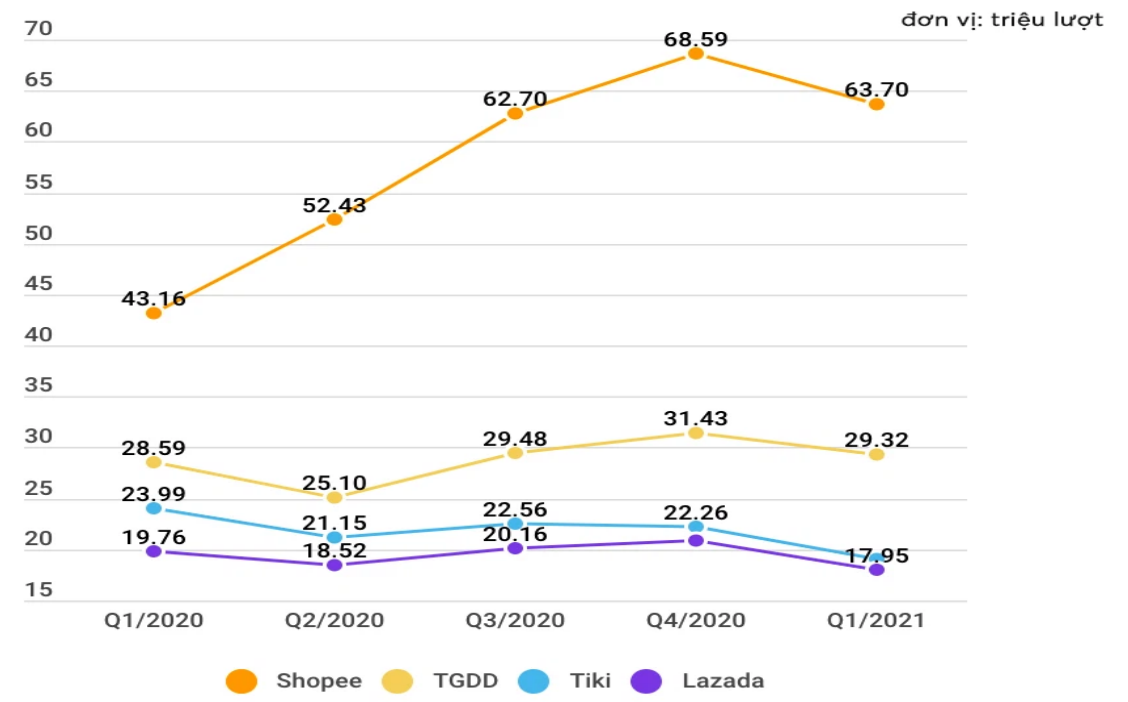

Hình 1. Thứ hạng 4 sàn TMĐT Việt Nam phổ biến trong năm 2020 và Quý I/2021. Số liệu: iPrice/SimilarWeb, đồ hoạ: Thái Sơn

Nhìn chung, 4 vị trí dẫn đầu bảng xếp hạng đều là những sàn TMĐT có lưu lượng truy cập nhất lớn nhất Việt Nam và không có sự khác biệt kể từ Quý I/2020. Theo đó, Shopee vẫn luôn là sàn TMĐT có nhiều lượt truy cập nhất trong mỗi 
tháng ở thị trường Việt Nam. Lưu lượng truy cập của Shopee vẫn tiếp tục đứng đầu và bỏ rất xa các sàn TMĐT khác. Cụ thể, Shopee đạt 63,7 triệu lượt truy cập, trong khi Thế Giới Di Động là 29,32 triệu, Tiki và Lazada lần lượt là 19 và 18 triệu. Như vậy, lượng truy cập của Shopee cao gấp hơn 2 lần Thế Giới Di Động, gấp hơn 3 lần so với Tiki và Lazada. Nếu so với Quý I/2020 thì chỉ có Shopee tăng trưởng (43,5\%), trong khi đó cả Thế Giới Di Động, Tiki và Lazada đều đi xuống hoặc đi ngang.(Thái Sơn, 2021)

Theo số liệu của iPrice Group và SimilarWeb, tổng số lượt truy cập vào top 50 sàn TMĐT hàng đầu Việt Nam trong hai quý đầu năm 2021 đạt hơn 1,3 tỷ lượt, đây là con số cao nhất từ trước đến nay. Số liệu cũng cho thấy lượt truy cập trong Quý II/2021 tăng 10\% so với Quý I/2021.

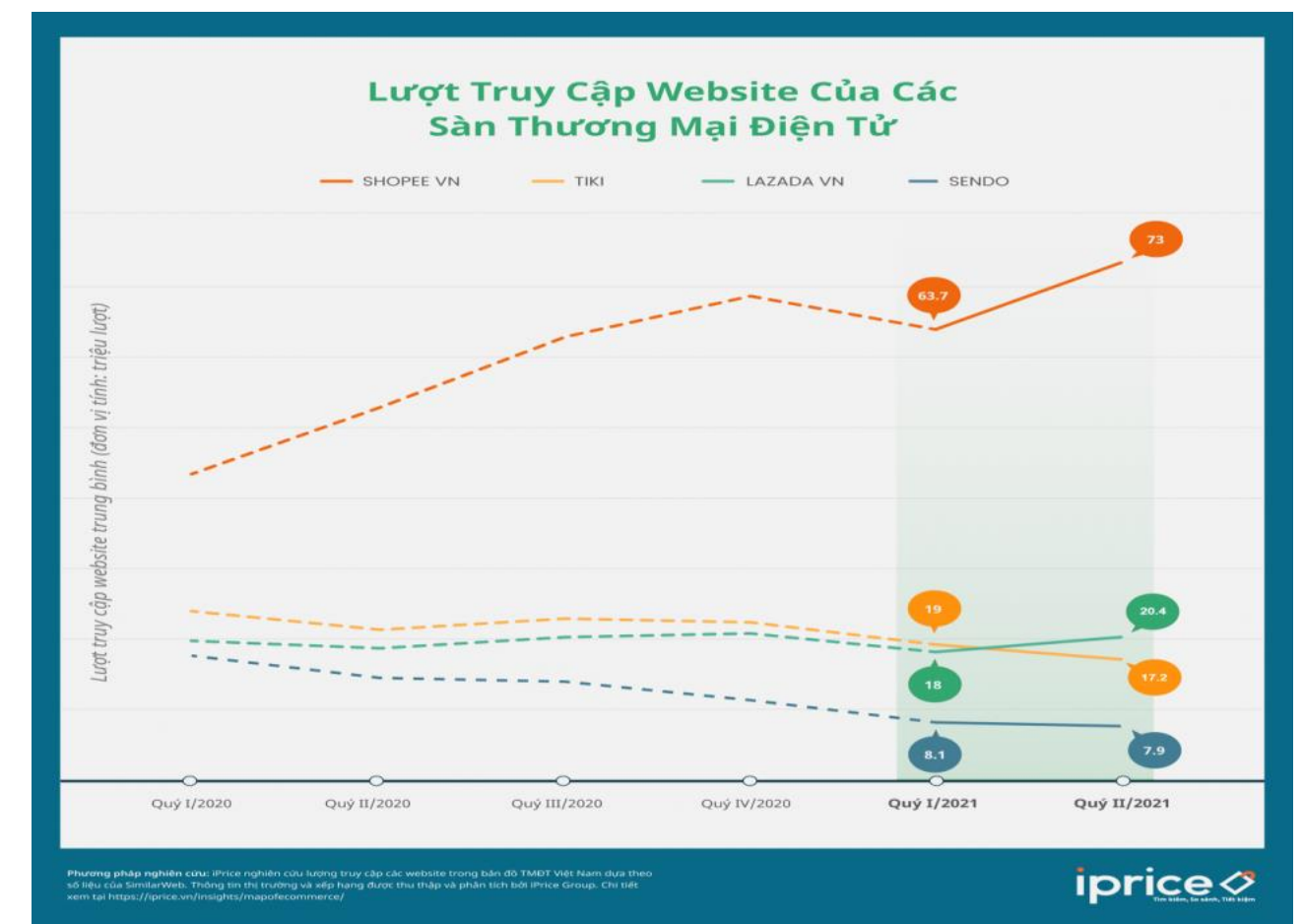

Hình 2. Thứ hạng 4 sàn TMĐT Việt Nam phổ biến trong Quý II/2021. Số liệu: iPrice/SimilarWeb

Trong 12 quý vừa qua, Shopee Việt Nam đứng đầu về lượng truy cập trang web trung bình. Sàn TMĐT này đạt 73 triệu lượt truy cập trong Quý II/2021, tăng 9,2 triệu so với Quý $\mathrm{I} / 2021$. Lazada Việt Nam vươn lên hạng 2 về lượt truy cập website các sàn TMĐT đa ngành sau nhiều tháng bị vượt mặt. Theo đó, lượt truy cập website trung bình của Lazada tăng 14\% so với Quý I và thu được 20,4 triệu lượt truy cập. Trong khi đó, lưu lượng truy cập của hai sàn TMĐT địa Tiki và Sendo có sự giảm nhẹ, lần lượt đạt 17,2 và 7,9 triệu lượt. "Như vậy, trật tự các doanh nghiệp TMĐT đa ngành tốp đầu ở quý II/2021 đã có sự thay đổi nhất định. 
Theo như xu hướng hiện tại, cuộc chơi lại dường như đang bị lấn át bởi các doanh nghiệp ngoại", đại diện iPrice Group đánh giá.(Nguyễn Nhất Duy, 2021)

Sang đến Quý III/2021, lượng truy cập website của top 4 sàn TMĐT đa ngành cho thấy 2 cái tên ngoại tiếp tục nới rộng khoảng cách với doanh nghiệp Việt. Shopee tiếp tục dẫn đầu với 77,8 triệu lượt truy cập, chiếm 57\% trong tổng số lượt truy cập trên tất cả các sàn TMĐT trong quý III, tăng 4.8 triệu lượt so với Quý II/2021. Lazada tục tăng trưởng và giữ nguyên vị trí ở vị trí thứ hai với 21,4 triệu lượt truy cập. Sau sự sụt giảm ở Quý II/2021, Tiki đã có sự tăng trưởng nhẹ lên 17,5 triệu lượt truy cập trong Quý III/2021. Sendo bị sụt giảm đến $40 \%$ lượng truy cập so với quý trước, giảm 3,2 triệu lượt so với Quý II/2021 xuống còn 4,7 triệu lượt truy cập.(Ban biên tập VTV Digital, 2021)

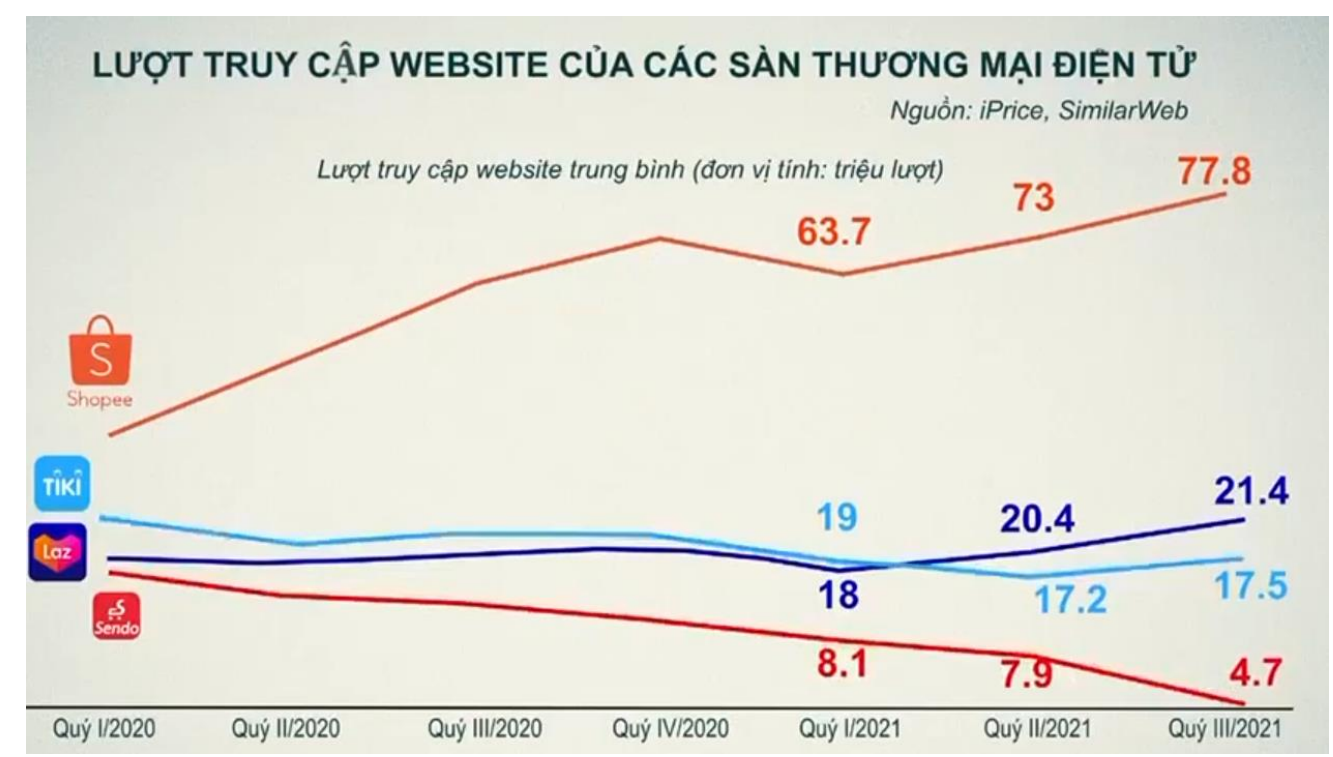

Hình 3. Thứ hạng 4 sàn TMĐT Việt Nam phổ biến trong Quý III/2021. Số liệu:

iPrice/SimilarWeb

\section{TIẾP CẬN VÀ GIẢI PHÁP PHÁT TRIỂN THƯƠNG MẠI ĐIỆN TỬ}

Xu hướng xã số hóa sẽ chi phối hầu hết các ngành và lĩnh vực, vì thế TMĐT có điều kiện để phát triển trong thời gian tới. Để thúc đẩy sự phát triển nhanh và bền vững lĩnh vực TMĐT tại Việt Nam, chúng tôi sử dụng hệ giải pháp sáng tạo 3D (Vuong, Q.H., 2022) để đề xuất một số khuyến nghị. Tập trung ưu tiên cho đầu tư vào khoa học công nghệ (Vuong, 2018) nhằm luôn tạo ra những tính năng, dịch vụ mới hữu ích. Đẩy mạnh truyền thông, thông tin, đảm bảo những thông tin có ích, hợp tác với các chuyên gia và các bên liên quan, thực hành kỷ luật xây văn hóa TMĐT nhằm tìm ra các giải pháp hữu ích và duy trì sự đóng góp của TMĐT cho sự tăng trưởng của đất nước.

\section{TÀI LIỆU THAM KHẢO:}

Ban biên tập Thông tấn xã Việt Nam. (2021). Thương mại điện tử và kinh tế số: Tăng trưởng 
chưa từng có tiền lệ. Cổng Thông Tin Điện Tử Sở Công Thương Hải Dương. http://sct.haiduong.gov.vn/Tin-moi/thuong-mai-dien-tu-va-kinh-te-so-tang-truongchua-tung-co-tien-le-ol7wPcwjjU.htm

Ban biên tập VTV Digital. (2021). "Nóng" cuộc đua bán thực phẩm tươ trên sàn TMĐT. Cổng Tin Điện Tử VTV Thông News. https://vtv.vn/kinh-te/nong-cuoc-dua-ban-thuc-phamtuoi-tren-san-tmdt-20211113100558655.htm

Ngọc, A. (2020). Doanh số bán hàng trực tuyến ở Mỹ tăng mạnh trong đại dịch. Báo Nhân Dân. https://nhandan.vn/tin-tuc-the-gioi/doanh-so-ban-hang-truc-tuyen-o-my-tangmanh-trong-dai-dich-613775/

Nguyễn Nhất Duy. (2021). Báo cáo TMĐT Quý II/2021: Bùng nổ nhu cầu tìm kiếm cưa hàng thiết yếu online. Iprice. https://iprice.vn/xu-huong/insights/bao-cao-tmdt-quy-ii2021bung-no-nhu-cau-tim-kiem-cua-hang-thiet-yeu-online/

Thái Sơn. (2021). TMĐT Việt quý I/2021: Shopee tăng trưởng hơn 40\%, các đối thủ lớn đi xuống hoặc đi ngang. Vietnambiz. https://vietnambiz.vn/tmdt-viet-quy-i-2021-minhshopee-tang-truong-hon-40-cac-doi-thu-lon-di-xuong-hoac-di-ngang20210601214737195.htm

UNCTAD, B. biên tập. (2020). eTrade for all initiatives. UNCTAD. https://unctad.org/topic/ecommerce-and-digital-economy/etrade-for-all

Vuong, Q.H., et al. (2022). Covid-19 vaccines production and societal immunization under the serendipity-mindsponge-3D knowledge management theory and conceptual framework. Humanities \& Social Sciences Communications, 9, 22. https://www.nature.com/articles/s41599-022-01034-6

Vuong, Q. H. (2018). The (ir)rational consideration of the cost of science in transition economies. Nature Human Behaviour, 2(1), 5. https://doi.org/10.1038/s41562-0170281-4 